\title{
Economic Lessons Are OK, Too
}

SEVERAL WEEKS AGO I had the pleasure of joining a group of nearly 100 high school students for a discussion about our oceans, coasts, and Great Lakes. The young men and women were participating in a conference in Washington, DC, designed to stimulate their curiosity about the marine environment. They came from all areas of the United States and all walks of life. At the end of their week in Washington, talking with bureaucrats, politicians, industry leaders, subject matter experts, and a variety of non-governmental organizations, the students were challenged to define a set of actions that they would try to undertake upon going home.

Their ideas were noble and inspired. Their young minds were unencumbered by the difficult realities that their actions would be sure to encounter, and the solutions they offered to problems in the marine environment were all heartfelt and provocative. These bright students addressed a rich diversity of issues, from pollution to climate change to coastal development to resource management. Whether the student was from a coastal state, like Alabama, or inland regions, such as Iowa, they focused their attention on important problems related to the stewardship of our oceans, coasts, and Great Lakes.

And I couldn't help but think that that might be a problem in itself.

Not one of the students discussed an action aimed at economic development, per se. Now say what you might about the innocence of youth, I think we've got to make stronger cases for convincing the next generation of the global population of the important financial and economic issues for which we oceanographers can take a leadership role. But before going any further, please recognize that I truly believe this can be done in careful balance with the essential concerns regarding stewardship of our oceans and their resources.

The argument is a simple one, really. The more we know about our ocean environment, the more we can turn that knowledge into marketable products and services. Just look at what's happened over the last 35 years in the private weather services sector. Customers are willing to pay a fair price for weather products and services that are tailored to their particular need—be it agriculture, energy management, or insurance. I would argue the marketability of ocean-based products and services could be overwhelming. Already commercial shippers and recreational boaters pay subscription fees for wave and current forecasts. Imagine the markets that might be available for forecasts of hypoxic events, or pinpoint wave-height predictions.

I wouldn't want to lose the sparkle and enthusiasm that the next generation demonstrated in the group that visited Washington last month, but I think we could supplement that with an additional perspective. Not all of those students will go on to careers in science. Many of them will go into business and policy development. Don't we owe it to them to see the potential for a stronger ocean-based economy? To do so, however, we want to make sure they recognize the need to build such an economy in a manner that is supportive of the delicate balances that Nature has crafted. What better time to convey that message than while they are still enthralled with the beauty and wonder of the world's oceans?

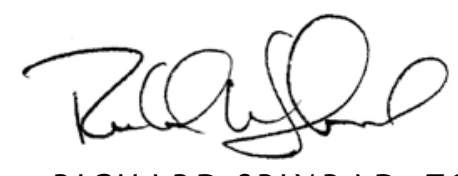

RICHARD SPINRAD, TOS PRESIDENT 